\title{
Fontes de fósforo em suplementos minerais para bovinos de corte em pastagem de Cynodon nlemfuensis Vanderyst ${ }^{1}$
}

\section{Silvana Teixeira², Antonio Ferriani Branco ${ }^{3}$, Fernanda Granzotto², Julio Cezar Barreto², Claudio Fabrício da Cruz Roma ${ }^{2}$, Romàn David Castañeda ${ }^{2}$}

\footnotetext{
1 Trabalho financiado pelo CNPq.

2 Programa de Pós-Graduação em Zootecnia/UEM. Avenida Colombo, 5790 - 87020-900 - Maringá, PR.

${ }^{3}$ Departamento de Zootecnia/UEM, Pesquisador CNPq. Avenida Colombo, 5790 - 87020-900 - Maringá, PR.
}

RESUMO - O experimento foi conduzido para avaliar quatro fontes de fósforo para bovinos em pastagem de grama-estrela roxa (Cynodon nlemfuensis Vanderyst) e compará-las considerando o desempenho ponderal e os parâmetros fisiológicos. O delineamento experimental foi o inteiramente casualizado, utilizando 32 animais mestiços (zebuíno $\times$ taurino), com peso inicial médio de $347 \mathrm{~kg}$, distribuídos ao acaso em quatro grupos, cada um recebendo suplemento mineral formulado com fosfato bicálcico, superfosfato triplo, fosfato monoamônio e fosfato de rocha de Araxá. O ganho de peso por hectare diferiu entre as datas de avaliação e teve redução significativa no último período, mas não entre as fontes de fósforo. O ganho médio diário não diferiu entre as fontes de fósforo e foi de 0,$67 ; 0,65 ; 0,63$ e $0,56 \mathrm{~kg} /$ dia, respectivamente, para fosfato bicálcico, superfosfato triplo, fosfato monoamônio e fosfato de rocha Araxá. As concentrações de osteocalcina mantiveram-se em níveis baixos $(47,67 \mathrm{ng} / \mathrm{mL})$ e foram semelhantes entre as fontes de fósforo. As fontes de fósforo foram eficientes em manter níveis adequados de fósforo no soro, com média de $7,03 \mathrm{mg} / 100 \mathrm{~mL}$.

Palavras-chave: minerais, osteocalcina, ruminantes, suplementação a pasto

\section{Phosphorus sources in mineral supplements for beef cattle grazing Cynodon nlemfuensis Vanderyst pasture}

\begin{abstract}
This study aimed to evaluate four sources of phosphorus for cattle grazing African Bermudagrass (Cynodon nlemfuesis Vanderyst) pasture and to compare them considering weight performance and physiological parameters. It was used a complete random experimental design, with 32 crossbred steers (Bos indicus $\times$ Bos Taurus) at average initial weight of $347 \mathrm{~kg}$ randomly distributed in four groups, each one receiving mineral supplement formulated with dicalcium phosphate, supertriple phosphate, monoammonium phosphate or Araxá rock phosphate, as sources of phosphorus. Weight gain per hectare differed among evaluation dates and it was significantly reduced in the last period, but it did not differ among sources of phosphorus. Average daily gain did not differ among sources of phosphorus and it was $0.67 ; 0.65 ; 0.63$ and $0.56 \mathrm{~kg} / \mathrm{day}$, respectively for dicalcium phosphate, supertriple phosphate, monoammonium phosphate and Araxá rock phosphate. Concentrations of osteocalcin were kept in low levels $(47.67 \mathrm{ng} / \mathrm{mL})$ and they were similar among sources of phosphorus. Sources of phosphorus were efficient in keeping appropriate levels of phosphorus in serum, with an average of $7.03 \mathrm{mg} / 100 \mathrm{~mL}$.
\end{abstract}

Key Words: minerals, osteocalcin, ruminants, supplementation at pasture

\section{Introdução}

Os sistemas pecuários brasileiros são caracterizados pela utilização de pastagens como principal alimento para o rebanho. As pastagens assumem dois aspectos importantes, viabilizam a competitividade brasileira e possibilitam a produção de forma natural, com respeito ao ambiente e aos animais (Euclides \& Medeiros, 2005).

As gramíneas do gênero Cynodon, constituídas por espécies e cultivares de ampla adaptação às diferentes condições edafoclimáticas (Oliveira et al., 2000), e portanto, importantes para a exploração pecuária bovina brasileira. No Brasil, o ciclo anual na produção de carne bovina pode ser dividido em dois períodos: o período das águas, quando a alta produção de forragem de qualidade resulta em elevada produção animal, e o período das secas, quando a produção limitada de pastagens retarda o crescimento animal ou provoca, até mesmo, perdas de peso.

Entre as causas da baixa produtividade do rebanho, a carência de minerais ocupa lugar de destaque. Na maioria das situações, as forrageiras não atendem integralmente às exigências dos animais em pastejo. $\mathrm{O}$ teor de minerais nas 
forrageiras varia amplamente e é influenciado principalmente pelos teores disponíveis no solo, mas fatores como déficit hídrico e maturidade da planta podem resultar em diminuição de alguns minerais na forrageira (Pedreira \& Berchielli, 2006).

Dentre os minerais que devem ser suplementados, o fósforo destaca-se pelo número e importância das funções que desempenha no organismo animal. Devido à deficiência generalizada desse mineral nas pastagens do Brasil Central, são indispensáveis à inclusão de fosfatos na mistura mineral fornecida aos bovinos em pastejo.

O fosfato bicálcico é uma das fontes de fósforo mais utilizadas na suplementação ao rebanho brasileiro, mas atualmente alguns fertilizantes fosfatados que possuem consideráveis teores de fósforo têm sido usados como fontes para ruminantes. Silva Filho et al. (1992) avaliando fontes suplementares relataram que o superfosfato triplo e o fosfato monoamônio possuem grande potencial quando utilizados como fonte de fósforo suplementar. Segundo Vitti et al. (1992), os fosfatos de rocha podem ser utilizados como fonte suplementar de fósforo, no entanto, o nível de flúor dessas fontes pode ser o fator limitante em dieta de ruminantes.

O experimento foi conduzido com o objetivo de avaliar quatro fontes de fósforo, ou seja, fosfato bicálcico, superfosfato triplo, monoamônio fosfato e fosfato de rocha, na suplementação de bovinos em pastagem, e compará-las quanto ao desempenho ponderal, concentração de fósforo e de osteocalcina no soro sanguíneo.

\section{Material e Métodos}

O experimento foi realizado na Fazenda Duas Fontes, município de Cruzeiro do $\operatorname{Sul}\left(22^{\circ} 58^{\prime}\right.$ de latitude sul e $52^{\circ} 0^{\prime}$ oeste de longitude), noroeste do estado do Paraná, localizada a 450 metros acima do nível do mar. O clima predominante na região é o $\mathrm{Cfa}$ - clima subtropical úmido mesotérmico, apresentando predominância de verões quentes, baixa freqüência de geadas severas e tendência de concentração das chuvas no período do verão (Tabela 1 ). O solo da região é classificado como Latossolo Vermelho Distrófico (Prado, 2003) composto por 52\% de areia grossa, 35\% de areia fina, $2 \%$ de silte e $11 \%$ de argila. As análises laboratoriais para avaliar a qualidade forrageira foram conduzidas no Laboratório de Análises de Alimentos e Nutrição Animal (LANA) do Departamento de Zootecnia/UEM.

A área experimental correspondeu a 13,46 ha, com grama-estrela roxa (Cynodon nlemfuensis Vanderyst) e foi dividida por cerca de arame liso, em quatro piquetes comáreas entre 3,3 e 3,4 ha. A água foi disponibilizada através de bebedouros com boia e os suplementos foram fornecidos em cochos de madeira cobertos (aproximadamente $0,2 \mathrm{~m} /$ animal).

Foram utilizados 32 novilhos não-castrados, mestiços (zebuínos $\times$ taurinos de corte), devidamente identificados, com 21 meses de idade e peso inicial médio de $347 \mathrm{~kg}$. Os animais foram pesados, sempre em jejum hídrico e alimentar prévio de 12 horas, ao início do período experimental e, a partir desta data, a cada 28 dias. As datas de avaliação de forragem e pesagem dos animais foram: 10/1/2007; 7/2/2007; 7/3/2007;3/4/2007 e 5/5/2007. Os animais foram distribuídos na área experimental de forma a obter homogeneidade dentro de cada grupo e de acordo com os ajustes na carga animal.

Antes do início do experimento os animais foram everminados e vacinados contra a febre aftosa e carbúnculo. Os animais foram colocados nos piquetes 15 dias antes do início do experimento, para adaptação, permaneceram todo o período experimental (115 dias) na pastagem de gramaestrela roxa e foram distribuídos em tratamentos que corresponderam a quatro fontes de fósforo: fosfato bicálcico; superfosfato triplo, fosfato monoamônio e fosfato de rocha Araxá (Tabela 2). As fontes de fósforo foram adicionadas na mistura em percentuais diferentes de forma a proporcionar concentração semelhante de cálcio e fósforo.

Os suplementos foram fornecidos no cocho à vontade, de modo que houvesse sobras para avaliar o consumo dos animais e a ingestão de cálcio e fósforo. $\mathrm{O}$ consumo foi determinado entre a diferença do fornecido ao início de cada período experimental e as sobras no cocho, de modo que, a cada 15 dias, por ocasião na mudança de piquete, o tratamento acompanhava os animais.

As fontes de fósforo foram analisadas (Tabela 3) quanto aos teores de cálcio (AOAC, 1990), fósforo (Fiske

Tabela 1 - Variáveis climáticas durante o período experimental

\begin{tabular}{lccr}
\hline Mês & Temperatura máxima $\left({ }^{\circ} \mathrm{C}\right)^{1}$ & Temperatura mínima $\left({ }^{\circ} \mathrm{C}\right)^{1}$ & Precipitação acumulada $(\mathrm{mm})$ \\
\hline Dezembro de 2006 & 32 & 24 & 220 \\
Janeiro de 2007 & 31 & 24 & 165 \\
Fevereiro de 2007 & 30 & 22 & 170 \\
Março de 2007 & 31 & 22 & 30 \\
Abril de 2007 & 30 & 22 & 15 \\
Maio de 2007 & 29 & 19 & 70 \\
\hline
\end{tabular}

${ }^{1}$ Média mensal. Fonte: Bratac - Cruzeiro do Sul. 
Tabela 2 - Composição percentual dos suplementos com as fontes de fósforo

\begin{tabular}{lcccc}
\hline Ingrediente $(\%)$ & \multicolumn{3}{c}{ Fonte de fósforo $^{1}$} \\
\cline { 2 - 5 } & Fosfato bicálcio & Superfosfato triplo & Fosfato monoamônio & Fosfato de rocha Araxá \\
\hline Tratamento & 32,50 & 27,30 & 25,00 & 56,60 \\
Calcário & 16,00 & 25,80 & 34,60 & - \\
$70 \mathrm{~S}$ & 6,90 & 6,90 & 6,90 & 6,90 \\
$\mathrm{MgO}$ & 7,30 & 7,30 & 7,30 & 7,30 \\
Premix & 3,00 & 3,00 & 3,00 & 3,00 \\
NaCl & 23,20 & 23,20 & 23,20 & 23,20 \\
Caulim & 11,10 & 6,50 & - & 3,00 \\
\hline
\end{tabular}

${ }^{1}$ As fontes de fósforo continham 6,$08 ; 5,86 ; 6,03$ e $6,76 \%$ de fósforo e 13,$66 ; 13,48 ; 13,16$ e 18,09\% de cálcio, respectivamente.

Composição da mistura mineral: magnésio - 0,5\%; sódio - $12 \%$; enxofre - 1,2\%; cobalto - 68 ppm; cobre - 1.240 ppm; iodo - 64 ppm; manganês - 1.120 ppm; selênio $-19,20 \mathrm{ppm}$ e zinco $-3.280 \mathrm{ppm}$.

Tabela 3 - Teores de fósforo, cálcio, flúor e solubilidade em ácido cítrico (2\%) nas diferentes fontes de fósforo utilizadas nas misturas minerais de bovinos

\begin{tabular}{lcccc}
\hline Fonte de fósforo & \multicolumn{3}{c}{ Variável } \\
\cline { 2 - 5 } & Fósforo $(\mathrm{g} / \mathrm{kg})$ & Cálcio $(\mathrm{g} / \mathrm{kg})$ & Flúor $(\mathrm{mg} / \mathrm{kg})$ & Solubilidade $(\%)$ \\
\hline Fosfato bicálcico & 187,00 & 236,00 & 1529,00 & 9982,50 \\
Superfosfato triplo & 214,50 & 139,50 & 5119,00 & 88,35 \\
Fosfato monoamônio & 241,00 & 7,62 & 14257,00 & 97,60 \\
Fosfato de rocha de Araxá & 119,50 & 322,50 & 19,85 \\
\hline
\end{tabular}

\& Subbarow, 1925) e flúor por potenciometria direta com eletrodo íon seletivo (Singer \& Armstrong, 1968) e quanto à solubilidade do fósforo (Duarte et al., 2003).

O ganho médio diário (GMD) foi obtido pela diferença entre o peso final e inicial dos animais, dividido pelo número de dias do intervalo (28) em cada período experimental. O ganho de peso por ha foi obtido multiplicando o número de animais/dia/ha pelo GMD dos animais, multiplicado pelo número de dias de cada período.

Durante o experimento, foi adotado o método de pastejo contínuo, com lotação fixa e carga variável (decorrente do ganho de peso) utilizando-se a técnica "Put and Take" (Mott \& Lucas, 1952). Cada grupo, com oito animais para cada fonte de fósforo, foi distribuído aleatoriamente nos piquetes no início do experimento, e os animais reguladores foram introduzidos em cada grupo, procurando manter a mesma oferta de forragem nos piquetes. A partir do início do experimento, a cada 15 dias, os grupos foram transferidos de um piquete para outro, seguindo o sentido horário, de forma a eliminar o efeito do piquete.

As estimativas da massa de forragem foram realizadas nos quatro piquetes, pelo método da dupla amostragem (Wilm etal., 1944). Para isso, foram observados aleatoriamente 27 pontos dentro de cada piquete, dos quais seis pontos foram coletados, as amostras cortadas ao nível do solo numa área de $0,56 \mathrm{~m}^{2}$, pesadas e secas em estufa com ventilação forçada de ar a $55^{\circ} \mathrm{C}$, por 72 horas. Utilizando-se os valores das amostras cortadas e estimadas visualmente, foi calculado o resíduo de matéria seca expressa em kg/ha (Gardner, 1986).
Para avaliar a taxa de acúmulo diário de MS (TA) e acúmulo total utilizaram-se três gaiolas de exclusão ao pastejo por piquete, e os cálculos realizados por intermédio da equação proposta por Campbell (1966): $\mathrm{TA}_{\mathrm{i}}=\mathrm{G}_{\mathrm{i}}-\mathrm{F}_{\mathrm{i}-1} / \mathrm{N}$. Em que: $\mathrm{TA}_{\mathrm{i}}=$ taxa de acúmulo diário de MS no período $i$, em kg MS/ha/dia; $\mathrm{G}_{\mathrm{i}}=$ MS dentro das gaiolas no instante $i$, em kg MS/ha; $\mathrm{F}_{\mathrm{i}-1}=$ MS fora das gaiolas no instante $i-1$, em $\mathrm{kg} \mathrm{MS} / \mathrm{ha} ; \mathrm{N}=$ número de dias do período $i$.

A taxa de lotação (TL) por piquete foi calculada considerando-se a unidade animal (UA) como sendo $450 \mathrm{~kg}$ de PV, utilizando-se a seguinte fórmula: $\mathrm{TL}=\mathrm{UAt} /$ Área. $\mathrm{TL}=$ taxa de lotação, em UA/ha; UAt = unidade animal total; Área $=$ área experimental, em ha.

A oferta de forragem (OF) foi calculada de duas formas, em uma foi considerada apenas a disponibilidade de forragem $(\mathrm{kg} / \mathrm{ha}$ de MS) e na outra, a disponibilidade e taxa de acúmulo: 1$) \mathrm{OF}=\mathrm{DMSD} / \mathrm{PV} \times 100$, em que: $\mathrm{OF}=$ em $\mathrm{kg} \mathrm{MS} / 100 \mathrm{~kg} \mathrm{PV/dia} \mathrm{ou} \mathrm{simplesmente} \mathrm{\% ;} \mathrm{DMSD} \mathrm{=}$ disponibilidade de matéria seca diária ( $\mathrm{kg}$ de MS/ha/dia); $\mathrm{PV}=$ peso dos animais, em $\mathrm{kg} / \mathrm{ha}$. 2) $\mathrm{OF}=(\mathrm{DMSD}+\mathrm{TAD}) /$ $\mathrm{PV} \times 100$, em que: $\mathrm{TAD}=$ taxa de acúmulo diário, em $\mathrm{kg}$ $\mathrm{MS} / \mathrm{ha} / \mathrm{dia}$.

Do material colhido na dupla amostragem foi feito o fracionamento em subamostras (aproximadamente 50\% do material) e separação dos componentes estruturais: lâmina foliar; bainha + colmo verde e material morto. Os materiais pertencentes às diferentes frações da planta foram secos em estufa com ventilação forçada de ar a $55^{\circ} \mathrm{C}$ por 72 horas e, posteriormente pesados. 
Na composição morfológica da pastagem determinou-se a percentagem de lâmina foliar, bainha + colmo verde e material morto, bem como a determinação da razão lâmina foliar/bainha + colmo verde. Para avaliar a composição bromatológica da lâmina foliar e bainha + colmo verde as amostras foram moídas em moinho tipo Willey com peneira de crivo de $1 \mathrm{~mm}$ e acondicionadas em potes plásticos para posteriormente determinar os teores de matéria seca (MS), matéria orgânica $(\mathrm{MO})$, cinzas, proteína bruta $(\mathrm{PB})$, extrato etéreo (EE) e cálcio pelo método AOAC (1990), fibra em detergente neutro (FDN), fibra em detergente ácido (FDA), lignina e celulose, segundo Van Soest et al. (1991), e fósforo, de acordo com Malavolta et al. (1997). As análises de digestibilidade in vitro da matéria seca da planta inteira, lâmina foliar e bainha + colmo verde foram realizadas de acordo com a metodologia de Tilley \& Terry (1963), adaptada para a utilização do rúmen artificial, desenvolvida por ANKON ${ }^{\circledR}$, conforme descrito por Holden (1999).

Para estimar os nutrientes digestíveis totais, os carboidratos não fibrosos (CNF) foram calculados pela seguinte equação (Sniffen et al., 1992): $\mathrm{CNF}=100-(\% \mathrm{FDN}$ $+\% \mathrm{~PB}+\% \mathrm{EE}+\%$ cinzas).

Os nutrientes digestíveis totais (NDT) foram estimados pela equação de predição proposta por Weiss (1999): NDT forragem $=\left[\mathrm{PB} * \mathrm{e}^{-0,012 * \mathrm{NIDA}}\right]+[0,98 * \mathrm{CNF}]+[0,90 *$ $(\mathrm{EE}-1) * 3,0]+\left\{0,75 *\left(\mathrm{FDN}_{\mathrm{PB}}-\mathrm{L}\right) *\left[1-\left(\mathrm{L} / \mathrm{FDN}_{\mathrm{PB}}\right)^{0,667}\right]\right\}$ -7 , em que: NIDA = nitrogênio insolúvel em detergente ácido; $\mathrm{FDN}_{\mathrm{PB}}=$ fibra em detergente neutro corrigida para proteína.

As amostras de sangue foram coletadas em todos os animais 14 dias após o início e 14 dias antes do término do experimento. O sangue foi coletado por venopunção em tubos a vácuo sem anticoagulante sendo posteriormente o soro sanguíneo obtido após centrifugação a 3.000 rpm por 15 minutos. Em seguida, o soro foi transferido para tubos do tipo eppendorf devidamente identificados por suplemento mineral, por animal e data e congelados a $-20^{\circ} \mathrm{C}$, para posteriores análises. O soro foi analisado para fósforo inorgânico (Little et al., 1971) e para concentração de osteocalcina utilizando o kit ELISA (Novocalcin, Metra Biosystems, Mountain View, CA) realizada no laboratório de endocrinologia da Universidade Federal de São Paulo Escola Paulista de Medicina (Unifesp).

O experimento foi conduzido em delineamento inteiramente casualizado, e os dados foram interpretados por uma análise de variância pelo procedimento "General Linear Model" adotando-se um nível de significância de $\mathrm{P}<0,05$ e o teste de Tukey a $5 \%$ de probabilidade utilizando o programa SAS (2001), de acordo com o seguinte modelo estatístico: $\mathrm{Y}_{\mathrm{ij}}=\mu+\mathrm{T}_{\mathrm{i}}+$ eij, em que: $\mathrm{Y}_{\mathrm{ij}}=$ valor observado das variáveis estudadas, relativo a cada indivíduo $\mathrm{j}$, recebendo a fonte de fósforo $\mathrm{i} ; \mu=$ constante geral; $\mathrm{Ti}=$ efeito da fonte de fósforo $\mathrm{i}$, com $\mathrm{i}$ variando de $1 \mathrm{a} 4 ; \mathrm{e}_{\mathrm{ij}}=$ erro aleatório associado a cada observação. Para as análises da forrageira o período foi considerado como Ti.

\section{Resultados e Discussão}

Os componentes estruturais da pastagem, lâmina foliar, bainha + colmo verde e material morto, são importantes para caracterizar a forragem disponível aos animais em pastejo. A porcentagem de lâmina foliar foi de $16,50 \%$ nos três primeiros períodos experimentais (Figura 1), mas reduziu para $13,45 \%$ no último período $(\mathrm{P}<0,05)$. A redução na proporção de lâmina foliar pode ser explicada pela redução na precipitação acumulada observada no mês de abril, que influenciou o crescimento da planta. A proporção de bainha + colmo verde não diferiu $(\mathrm{P}>0,05)$ entre os períodos de avaliação, com proporção média de $48,07 \%$, e foi o componente com maior participação em todo o período experimental(Figura 1). Assim como a bainha + colmo verde, o material morto não foi influenciado pelo período, com porcentagem média de $36,20 \%$.

A disponibilidade de matéria seca (Tabela 4) não diferiu $(\mathrm{P}>0,05)$ entre os períodos de coleta, com disponibilidade média de $2.331 \mathrm{~kg}$ de MS/ha. Esses valores são próximos aos preconizados por Corsi \& Martha Júnior (1998) para gramíneas do gênero Cynodon, que devem apresentar resíduo de aproximadamente $2.500 \mathrm{~kg}$ de MS/ha. Hodgson (1990) e Minson (1990) relataram que $2.000 \mathrm{~kg}$ de MS/ha é o mínimo para que a disponibilidade não prejudique o consumo da pastagem, em decorrência redução do tamanho de bocados, o que acarreta em maior tempo de pastejo.

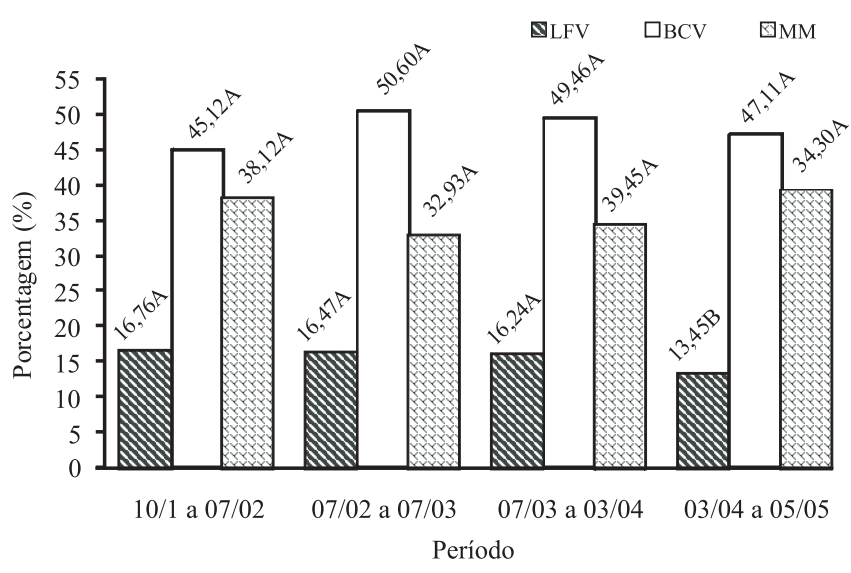

Figura 1 - Lâmina foliar verde (LFV), bainha + colmo verde $(\mathrm{BCV})$ e material morto (MM) de grama-estrela roxa em cada período experimental. 
Tabela 4 - Disponibilidade de componentes da planta em cada período experimental

\begin{tabular}{|c|c|c|c|c|c|}
\hline \multirow[t]{2}{*}{ Data } & \multicolumn{5}{|c|}{ Componente da planta ( $\mathrm{kg}$ de $\mathrm{MS} / \mathrm{ha}$ ) } \\
\hline & Matéria seca & Lâmina foliar verde & Bainha + colmo verde & Material morto & $\mathrm{LF} / \mathrm{BCV}$ \\
\hline $10 / 1-7 / 2 / 2007$ & 2180 & 368 & 994 & 819 & $0,37 \mathrm{a}$ \\
\hline $7 / 2-7 / 3 / 2007$ & 2394 & 394 & 1230 & 770 & $0,33 \mathrm{ab}$ \\
\hline $7 / 3-3 / 4 / 2007$ & 2492 & 405 & 1258 & 829 & $0,33 a b$ \\
\hline $3 / 4-5 / 5 / 2007$ & 2257 & 307 & 1080 & 870 & $0,29 b$ \\
\hline Média & 2331 & 369 & 1141 & 822 & 0,33 \\
\hline EPM & $\pm 332,15$ & $\pm 56,83$ & $\pm 204,21$ & $\pm 76,54$ & $\pm 0,01$ \\
\hline
\end{tabular}

a,b,c Letras iguais na mesma coluna indicam igualdade $(\mathrm{P}>0,05)$ pelo teste Tukey.

EPM - erro-padrão da média; LFV/BCV - razão LFV (lâmina foliar verde) e BCV(bainha + colmo verde).

Apesar do valor obtido para disponibilidade média de matéria seca ter sido superior a $2.000 \mathrm{~kg} / \mathrm{ha}$ de MS, a disponibilidade média de lâmina foliar e bainha + colmo verde não totalizam valores superiores a $2.000 \mathrm{~kg}$ de MS/ha, em virtude da elevada proporção de material morto, que foi em média $869 \mathrm{~kg}$ de MS/ha.

O período de coleta não influenciou a disponibilidade de lâmina foliar, de bainha + colmo verde e de material morto (Tabela 4). A disponibilidade de material morto ( $822 \mathrm{~kg}$ de $\mathrm{MS} / \mathrm{ha}$ ) foi semelhante aos estudos realizados por Bortolo et al. (2001) que trabalhando com ovinos em pastagem de Cynodon sp, verificou que o aumento na disponibilidade de massa seca da pastagem, reduzia a disponibilidade de material morto expressas em $\mathrm{kg}$ de $\mathrm{MS} / \mathrm{ha}$. A razão lâmina foliar/bainha + colmo verde foi influenciada $(\mathrm{P}<0,05)$ pelos períodos de avaliação. O primeiro período de avaliação apresentou maior razão lâmina/bainha + colmo verde, em relação ao último período. Segundo Van Soest (1994), o avanço na idade da maturidade das forrageiras além de diminuir a razão lâmina/colmo, leva a queda na digestibilidade.

$\mathrm{O}$ acúmulo de massa de forragem e o acúmulo diário de massa de forragem apresentaram diferenças $(\mathrm{P}<0,05)$ nas datas de amostragem. Foi observada redução (Tabela 5) no acúmulo de massa de forragem com o avanço nos períodos de avaliação. Como antes do início do experimento (mês de dezembro) as condições climáticas foram favoráveis (alta temperatura e alta da precipitação pluviométrica), o maior acúmulo de massa de forragem (AMF) foi obtido no mês de janeiro onde a produção foi de $2053 \mathrm{~kg}$ de MS $/ \mathrm{ha}(73 \mathrm{~kg}$ de MS/ha/dia) (Tabela 5). Estes valores estão próximos aos relatados por Pedreira \& Mattos (1981) que avaliando Cynodon dactylon cv. Coastcross obtiveram acúmulo diário de massa de forragem no mês de dezembro de $84 \mathrm{~kg}$ de MS/ha/dia. No período que corresponde aos meses de março e abril foram obtidos os menores valores de acúmulo de massa de forragem, com acúmulos de 1158 (43 kg de $\mathrm{MS} / \mathrm{ha} / \mathrm{dia}$ ) e $729 \mathrm{~kg}$ de MS/ha (23 kg de MS/ha/dia), os quais diferiram $(\mathrm{P}<0,05)$ da taxa de acúmulo obtida no mês de janeiro. Segundo Brougham (1957), durante o desenvolvimento vegetativo da forrageira, há três fases distintas para taxa de acúmulo. Na primeira fase representada aqui pelo primeiro período experimental, a taxa de acúmulo líquido de forragem aumenta exponencialmente, o que pode ser influenciada por reservas orgânicas da forrageira, disponibilidade de fatores de crescimento e área residual de folhas. A segunda fase, representada pelo segundo e terceiro período, comprova que taxas de acúmulo são

Tabela 5 - Acúmulo de massa de forragem, acúmulo diário de massa de forragem, oferta de forragem de grama-estrela roxa e taxa de lotação em cada período experimental

\begin{tabular}{|c|c|c|c|c|c|}
\hline \multirow[t]{3}{*}{ Data } & \multicolumn{5}{|c|}{ Variável } \\
\hline & $\begin{array}{l}\text { Acúmulo de massa } \\
\text { de forragem }\end{array}$ & $\begin{array}{l}\text { Acúmulo diário } \\
\text { de massa de forragem }\end{array}$ & $\begin{array}{l}\text { Oferta de } \\
\text { forragem }{ }^{1}\end{array}$ & $\begin{array}{l}\text { Oferta de } \\
\text { forragem }^{2}\end{array}$ & $\begin{array}{l}\text { Taxa de } \\
\text { lotação }\end{array}$ \\
\hline & \multicolumn{2}{|c|}{$\mathrm{kg}$ de $\mathrm{MS} / \mathrm{ha}$ de $\mathrm{MS}$} & \multicolumn{2}{|c|}{$\mathrm{kg}$ de $\mathrm{MS} / 100 \mathrm{~kg} \mathrm{PV} / \mathrm{dia}$} & (UA/ha) \\
\hline $10 / 1-7 / 2 / 2007$ & $2053 \mathrm{a}$ & $73 a$ & $8,75 \mathrm{ab}$ & $17,05 \mathrm{a}$ & $2,03 \mathrm{a}$ \\
\hline $7 / 2-7 / 3 / 2007$ & $1326 \mathrm{ab}$ & $47 \mathrm{ab}$ & $10,10 \mathrm{a}$ & $15,81 \mathrm{a}$ & $1,88 \mathrm{a}$ \\
\hline $7 / 3-3 / 4 / 2007$ & $1158 b$ & $43 b$ & $9,67 \mathrm{a}$ & $14,26 \mathrm{a}$ & $2,10 \mathrm{a}$ \\
\hline $3 / 4-5 / 5 / 2007$ & $729 b$ & $23 b$ & $6,59 b$ & $8,93 b$ & $2,30 \mathrm{a}$ \\
\hline Média & 1317 & 47 & 8,78 & 14,01 & 2,08 \\
\hline EPM & $\pm 202,31$ & $\pm 7,18$ & $\pm 0,71$ & $\pm 1,06$ & $\pm 0,15$ \\
\hline
\end{tabular}

${ }^{1}$ Oferta de forragem considerando apenas a disponibilidade de matéria seca (kg/ha/dia de MS); ${ }^{2} \mathrm{OF}$ - Oferta de forragem considerando disponibilidade de matéria seca de forragem e taxa de acúmulo $(\mathrm{kg} / \mathrm{ha} /$ dia de MS).

a,b,c Letras iguais nas colunas indicam igualdade $(\mathrm{P}>0,05)$ pelo teste Tukey.

EPM - erro-padrão da média. 
constantes, e a terceira fase, ocorrida no quarto período experimental, quando se inicia a queda nas taxas de acúmulo, causada pela redução na taxa de crescimento e pelo aumento na senescência de folhas. Com o avanço na idade da planta ocorre redução no crescimento da forragem, resultando no aumento da parede celular, aumento na lignificação e senescência da mesma, promovendo um menor acúmulo de massa de forragem.

A oferta de forragem foi influenciada $(\mathrm{P}<0,05)$ pelo período de avaliação (Tabela 5), resultado da redução na disponibilidade de forragem. Segundo Da Silva \& Pedreira (1997), um dos fatores determinantes do consumo em pastagens é a oferta de forragem. A oferta de forragem 1 diferiu $(\mathrm{P}<0,05)$ do segundo e terceiro período em relação ao quarto período. No entanto para a oferta de forragem $2 \mathrm{o}$ primeiro, segundo e terceiro período de avaliação foram semelhantes entre si, diferindo $(\mathrm{P}<0,05)$ apenas do quarto período.

O teor de matéria seca da lâmina foliar e bainha + colmo verde diferiu $(\mathrm{P}<0,05)$ entre os períodos de avaliação, e as respostas com o avanço dos períodos de coleta foram semelhantes (Tabela 6), sendo que, à medida que avançou o período de coleta o teor de matéria seca da pastagem também aumentou. A proteína bruta da lâmina foliar foi em média $13,98 \%$, valor que está acima de $7 \%$ de PB considerado mínimo para suprir as necessidades das bactérias ruminais (Moore et al., 1991) e não prejudicar o consumo voluntário dos animais (Minson, 1990), pressupondo que a maior seletividade dos animais seja pela parte aérea da planta.
A concentração média de FDN encontrada na lâmina foliar e bainha + colmo verde foram semelhantes (Tabela 6 ). Os valores estão próximos aos obtidos por Oliveira et al. (2000) para capim-tifton 85 aos 56 e 49 dias de rebrote, com teores de FDN para lâmina foliar e bainha + colmo verde, na ordem de 81,7 e $80,2 \%$, respectivamente, e superiores aos obtidos por Prohmann et al. (2004), que observou valores para lâmina foliar e bainha + colmo verde entre 65,1 e 74,9\%.

As concentrações de cálcio da bainha + colmo verde tiveram uma redução gradativa com o avanço na idade da planta, no entanto, seus teores não tiveram redução significativa $(\mathrm{P}>0,05)$ na lâmina foliar (Tabela 6). De acordo com Minson (1990), as concentrações de cálcio nas folhas são mais elevadas do que na bainha + colmo verde. Para algumas forrageiras com estádio de maturidade menos avançado, as concentrações de cálcio chegam as ser duas vezes superiores para folhas quando comparadas com bainha + colmo verde, exemplo é a espécie Digitaria decumbens que apresenta concentrações de $3,7 \mathrm{~g} \mathrm{de} \mathrm{Ca} / \mathrm{kg}$ de MS nas folhas e 1,2 g de Ca/kg de MS na bainha + colmo verde (Minson, 1990).

As concentrações de fósforo tanto para lâmina como para bainha + colmo verde não foram influenciadas $(\mathrm{P}>0,05)$ pelos períodos de avaliação. $O$ acúmulo de fósforo é igual na lâmina foliar e bainha + colmo verde, e em ambas as partes da planta estes valores foram inferiores a $0,14 \%$. Butterworth (1985) destaca que níveis inferiores a $0,18 \%$ indicam provável deficiência desse elemento para a maioria das categorias animais, sendo necessária a suplementação.

Tabela 6 - Composição bromatológica dos componentes estruturais da planta e digestibilidade in vitro da matéria seca (DIVMS) de grama-estrela roxa em cada período experimental

\begin{tabular}{|c|c|c|c|c|c|c|}
\hline \multirow[t]{2}{*}{ Item } & \multicolumn{4}{|c|}{ Componentes estruturais (\%) } & \multirow[b]{2}{*}{ Média } & \multirow[b]{2}{*}{ EPM } \\
\hline & $10 / 1-7 / 2 / 2007$ & $7 / 2-7 / 3 / 2007$ & $7 / 3-3 / 4 / 2007$ & $3 / 4-5 / 5 / 2007$ & & \\
\hline \multicolumn{7}{|c|}{ Lâmina foliar } \\
\hline Proteína bruta & 14,37 & 14,04 & 13,60 & 13,93 & 13,98 & $\pm 0,63$ \\
\hline Fibra em detergente neutro & 81,70 & 80,68 & 81,56 & 81,04 & 81,25 & $\pm 0,74$ \\
\hline Cálcio & 0,38 & 0,37 & 0,36 & 0,35 & 0,37 & $\pm 0,01$ \\
\hline DIVMS & 53,15 & 53,02 & 54,07 & 53,29 & 53,39 & $\pm 2,76$ \\
\hline \multicolumn{7}{|c|}{ Bainha + colmo verde } \\
\hline Matéria seca & $35,09 \mathrm{c}$ & $37,91 \mathrm{bc}$ & $40,67 \mathrm{ab}$ & $42,65 \mathrm{a}$ & 30,08 & $\pm 0,89$ \\
\hline Proteína bruta & 5,29 & 4,19 & 3,94 & 3,56 & 4,25 & $\pm 0,49$ \\
\hline Fibra em detergente neutro & 81,27 & 80,94 & 81,53 & 81,28 & 81,25 & $\pm 0,34$ \\
\hline Cálcio & $0,14 \mathrm{a}$ & $0,13 \mathrm{ab}$ & $0,13 \mathrm{ab}$ & $0,12 b$ & 0,13 & $\pm 0,004$ \\
\hline DIVMS & 39,73 & 41,66 & 41,21 & 39,38 & 40,50 & $\pm 0,96$ \\
\hline
\end{tabular}

DIVMS = digestibilidade in vitro da matéria seca; EPM - erro-padrão da média.

a,b,c,d Letras iguais na mesma linha indicam igualdade $(\mathrm{P}>0,05)$ pelo teste Tukey. 
A digestibilidade in vitro da matéria seca não foi influenciada $(\mathrm{P}>0,05)$ pelos períodos experimentais, tanto para lâmina foliar, bainha + colmo verde e planta inteira (Tabela 6). Os valores de digestibilidade da lâmina foliar, bainha + colmo verde e planta inteira estão abaixo dos considerados ideais para um bom desenvolvimento microbiano, que de acordo com Nussio et al. (1998), fica entre 65 a 70\%. A baixa digestibilidade da planta inteira pode ter sido influenciada pela grande proporção de material morto na massa de forragem (Figura 1).

O ganho de peso por hectare (GPA) diminuiu com o avanço do período de avaliação (Tabela 7). O maior ganho de peso ocorreu em janeiro/fevereiro (10/01 a 07/02) com $61,75 \mathrm{~kg} / \mathrm{ha}$, onde as condições climáticas (Tabela 1) favoreceram a produtividade e qualidade da pastagem e consequentemente influenciaram de forma direta o desempenho ponderal dos animais. O menor ganho de peso ocorreu em abril/maio (3/4 a 5/5) com ganho de $33,00 \mathrm{~kg} / \mathrm{ha}$, o qual foi desfavorecido pelas condições climáticas com baixa precipitação pluviométrica acumulada inferior aos demais períodos, refletindo em baixa produtividade e qualidade forrageira. Moreira et al. (2004), utilizando animais em pastejo de grama-estrela roxa com baixa produção de massa de forragem obtiveram ganho de $34 \mathrm{~kg} / \mathrm{ha}$, semelhante ao ganho obtido neste experimento no último período de coleta $(33 \mathrm{~kg} / \mathrm{ha})$. A redução no ganho por área ocorreu como resultado do declínio na produção e na qualidade da

Tabela 7 - Ganho de peso/ha de bovinos mestiços em pastagens de grama-estrela roxa recebendo suplementação com fontes de fósforo

\begin{tabular}{lc}
\hline Período & Ganho de peso por área \\
\hline $10 / 1-7 / 2 / 2007$ & $61,75 \mathrm{a}$ \\
$7 / 2-7 / 3 / 2007$ & $43,75 \mathrm{ab}$ \\
$7 / 3-3 / 4 / 2007$ & $39,00 \mathrm{ab}$ \\
$3 / 4-5 / 5 / 2007$ & $33,00 \mathrm{~b}$ \\
Total & 177,50 \\
EPM & $\pm 7,12$ \\
\hline
\end{tabular}

a,b,c Letras iguais na mesma coluna indicam igualdade $(\mathrm{P}>0,05)$ pelo teste Tukey. EPM - erro-padrão da média. forrageira, mas considerando a produtividade de carne no Brasil, o ganho obtido neste experimento, que totalizou $177,5 \mathrm{~kg} / \mathrm{ha}$ num período de 115 dias, foi satisfatório.

$\mathrm{O}$ ganho de peso/ha não foi influenciado pelas fontes de fósforo $(\mathrm{P}>0,05)$, e os ganhos obtidos com o fosfato bicálcico, fosfato de rocha Araxá, fosfato monamônio e superfosfato triplo foram 53,$5 ; 38,0 ; 47,25 ;$ e $38,75 \mathrm{~kg} / \mathrm{ha}$, respectivamente.

O ganho médio diário $(\mathrm{kg} / \mathrm{dia})$ não foi influenciado pelas fontes de fósforo $(\mathrm{P}>0,05)$, indicando que essas fontes de fósforo podem proporcionar desempenhos semelhantes (Tabela 8). Esses resultados indicam que, mesmo para animais em crescimento, a fonte de fósforo suplementar pode não ter influência significativa na resposta animal, e que outros fatores como, oferta de massa de forragem, oferta de lâmina foliar e razão lâmina foliar/bainha + colmo verde, podem ser mais importantes.

A maturidade da planta, a redução na produção de folhas e aumento na proporção de colmo e material morto, a redução na qualidade da proteína da forragem e o aumento na concentração dos componentes da parede celular diminuem desempenho ponderal dos animais, como pode ser visualizados no terceiro e quarto períodos de avaliação. Essa redução foi muito mais expressiva no quarto período experimental, pois o ganho de peso médio variou entre 0,20 (fosfato de rocha Araxá) e $0,63 \mathrm{~kg}$ (fosfato bicálcico), notando-se que os ganhos acompanharam as respostas oriundas da qualidade de forragem, mas muito mais de sua produção, certamente, proporcionando grande seletividade animal. Quando se avalia o ganho de peso médio em relação aos períodos experimentais, é observada a influência do período em relação à média dos ganhos, independentemente da fonte de fósforo.

Para o consumo médio do suplemento mineral foi realizada apenas análise descritiva, sendo que o maior consumo foi para superfosfato triplo e o menor consumo para fosfato de rocha Araxá (Tabela 9). A baixa ingestão de fosfato de rocha Araxá é decorrente da baixa aceitabilidade

Tabela 8 - Ganho médio diário ( $\mathrm{kg} / \mathrm{dia}$ ) de bovinos em pastagem de grama-estrela roxa recebendo suplementação com fontes de fósforo

\begin{tabular}{|c|c|c|c|c|c|c|}
\hline \multirow[t]{2}{*}{ Fonte de fósforo } & \multicolumn{4}{|c|}{ Data } & \multirow[b]{2}{*}{ Média } & \multirow[b]{2}{*}{ EPM } \\
\hline & $10 / 1-7 / 2 / 2007$ & $7 / 2-7 / 3 / 2007$ & $7 / 3-3 / 4 / 2007$ & $3 / 4-5 / 5 / 2007$ & & \\
\hline Fosfato bicálcico & $0,84 \mathrm{aA}$ & $0,79 \mathrm{aA}$ & $0,41 \mathrm{bB}$ & $0,63 \mathrm{aAB}$ & $0,67 \mathrm{a}$ & $\pm 0,09$ \\
\hline Superfosfato triplo & $0,89 \mathrm{aA}$ & $0,65 \mathrm{abAB}$ & $0,62 \mathrm{abAB}$ & $0,43 \mathrm{abB}$ & $0,65 \mathrm{a}$ & $\pm 0,11$ \\
\hline Fosfato monoamônio & $0,69 \mathrm{aA}$ & $0,84 \mathrm{aA}$ & $0,58 \mathrm{abA}$ & $0,42 \mathrm{abA}$ & $0,63 \mathrm{a}$ & $\pm 0,11$ \\
\hline Fosfato de rocha Araxá & $0,83 \mathrm{aA}$ & $0,36 \mathrm{bB}$ & $0,84 \mathrm{aA}$ & $0,20 \mathrm{bB}$ & $0,56 \mathrm{a}$ & $\pm 0,10$ \\
\hline Médias & $0,81 \mathrm{a}$ & $0,66 \mathrm{a}$ & $0,61 \mathrm{ab}$ & $0,42 b$ & 0,63 & - \\
\hline EPM & $\pm 0,93$ & $\pm 0,10$ & $\pm 0,11$ & $\pm 0,10$ & $\pm 0,04$ & \\
\hline & $\pm 0,11^{1}$ & $\pm 0,11^{1}$ & $\pm 0,12^{1}$ & $\pm 0,11^{1}$ & $\pm 0,05^{1}$ & - \\
\hline
\end{tabular}

a,b,c Letras iguais na mesma coluna, indicam igualdade $(\mathrm{P}>0,05)$ pelo teste Tukey; $\mathrm{A}, \mathrm{B}, \mathrm{C}$ Letras iguais na mesma linha indicam igualdade $(\mathrm{P}>0,05)$ pelo teste Tukey. EPM - erro-padrão da média; ${ }^{1} \mathrm{EPM}$ - erro-padrão da média com número de repetições diferentes para o superfosfato triplo. 
desta fonte de fósforo, que, por sua vez, acaba por afetar o consumo (Dayrell, 1991; Vitti et al., 1992).

A ingestão de fósforo e cálcio ( $\mathrm{g} / \mathrm{animal} / \mathrm{dia}$ ) foram maiores com o superfosfato triplo, e a menor ingestão desses minerais foi obtida com a fonte fosfato de rocha Araxá e fosfato monoamônio (Tabela 9). A ingestão de flúor teve grande variação entre as fontes de fósforo; a menor ingestão foi verificada com o uso de fosfato bicálcico e a maior com o uso de fosfato de rocha Araxá. O NRC (1996) adota como nível tolerável para gado de corte concentrações entre 20 e 100 ppm, dependendo da categoria animal. Segundo Underwood (1981), por ser menos absorvido, os bovinos toleram mais o flúor proveniente dos fosfatos de rocha do que o fluoreto de sódio, neste caso, o nível na dieta não deve ultrapassar $30 \mathrm{ppm}$ para animais em crescimento e, quando o flúor é oriundo de rocha, o animal tolera nível mais elevado. Nicodemo \& Moraes (2000) relataram que, para bovinos adultos, é tolerável ingestão de $50 \mathrm{mg}$ de $\mathrm{F} / \mathrm{kg}$ de MS consumida.

As concentrações de osteocalcina (marcador de formação óssea) e fósforo inorgânico no soro sanguíneo dos animais não apresentaram diferenças $(\mathrm{P}>0,05)$ entre as fontes de fósforo nem as datas de coleta (Tabela 10). A osteocalcina teve comportamento semelhante ao do fósforo inorgânico, resultados que confirmam os obtidos por Naito et al. (1990). Nicodemo et al. (2005) estudaram diferentes tipos de suplementos e encontraram concentrações semelhantes de osteocalcina em vacas após o terço final de lactação. As concentrações de osteocalcina estão relacionadas à quantidade de osteocalcina que entra na circulação sanguínea, que depende da taxa de secreção individual dos osteoblastos e do número de osteoblastos que secretam a proteína (Nielsen, 1994). Os dados obtidos para fósforo inorgânico (Tabela 10) estão nos limites considerados normais, entre 4 e 9 mg/dL (Thompson Júnior, 1978; NRC, 1974). Valores inferiores aos encontrados neste trabalho, e também dentro da normalidade, foram observados por Barreto et al. (2009) em pesquisa com as mesmas fontes de fósforo.

As observações sobre as concentrações plasmáticas de fósforo devem ser interpretadas com cautela, pois, de acordo com Bortolussi et al. (1996), quando o fósforo na dieta não é um fator limitante, o fósforo inorgânico no plasma pode estar em faixa normal ou acima dela e em prolongados períodos de seca, quando há deficiência de

Tabela 9 - Consumo de suplemento mineral, ingestão de fósforo, cálcio e flúor pela mistura mineral por bovinos de corte

\begin{tabular}{lcrrr}
\hline Parâmetro & \multicolumn{4}{c}{ Fonte de fósforo } \\
\cline { 2 - 5 } & Fosfato bicálcico & Superfosfato triplo & Fosfato monoamônio & Fosfato de rocha Araxá \\
\hline g/animal/dia & 56,57 & 68,04 & 43,22 & 33,37 \\
Fósforo, g/dia & 3,44 & 3,97 & 2,61 & 2,26 \\
Cálcio, g/dia & 7,73 & 9,17 & 5,69 & 6,09 \\
Flúor, mg/dia & 28,13 & 92,50 & 55,32 & 269,13 \\
\hline
\end{tabular}

Tabela 10 - Concentrações de osteocalcina e fósforo inorgânico de bovinos suplementados com fontes de fósforo

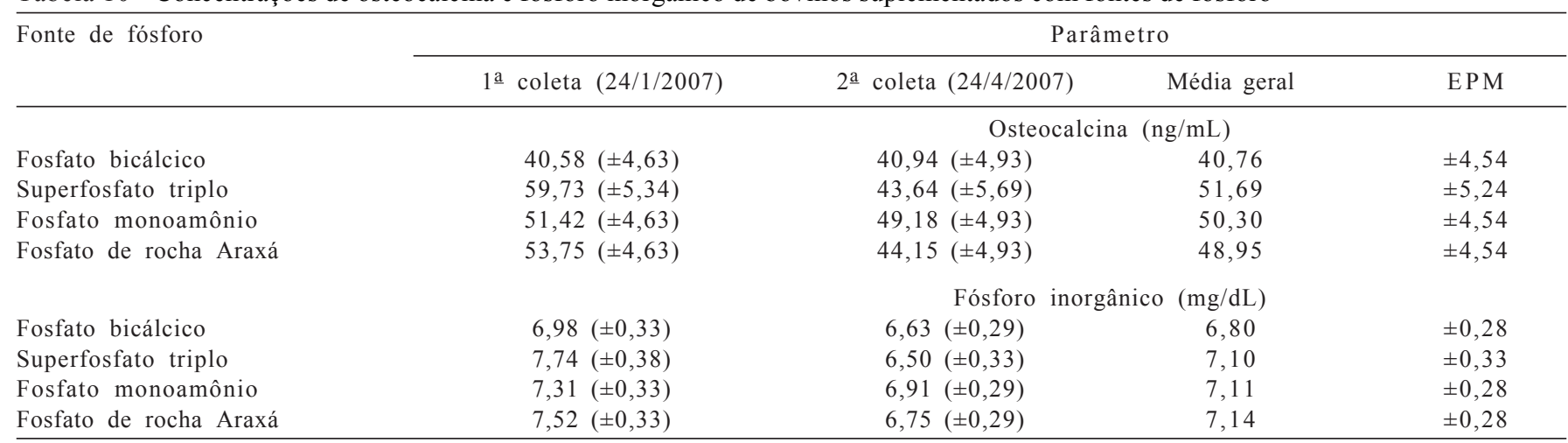

a,b,c Letras iguais na mesma coluna indicam igualdade $(\mathrm{P}>0,05)$ pelo teste Tukey. EPM: erro-padrão da média.

fósforo e de proteína, com redução no consumo de alimento, os animais perdem peso e há reabsorção óssea, resultando em elevação do fósforo plasmático, apesar de os animais estarem com deficiência de fósforo.

\section{Conclusões}

O desempenho ponderal de bovinos de corte em pastagem de grama-estrela roxa está diretamente relacionado 
à produção de massa e qualidade de forragem e à razão lâmina/colmo. Todas as fontes de fósforo são eficientes em manter níveis normais de osteocalcina e fósforo inorgânico na corrente sanguínea, assim, a opção pela fonte de fósforo a ser suplementada depende de sua viabilidade econômica e do tempo de suplementação desejado, uma vez que todas as fontes promovem respostas semelhantes.

\section{Referências}

ASSOCIATION OF OFFICIAL ANALITICAL CHEMISTS - AOAC. Official methods of analysis. 15.ed. Arlington, 1990.

BARRETO, J.C.; BRANCO, A.F.; SANTOS, G.T. et al. Avaliação dos efeitos de fontes de fósforo na dieta sobre parâmetros do meio ruminal e eficiência de síntese microbiana, digestibilidade dos nutrientes e fósforo plasmático em bovinos. Revista Brasileira de Zootecnia, v.38, n.4, p.760-769, 2009.

BORTOLO, M.; CECATO, U.; MARTINS, E.N. et al. Avaliação de uma pastagem de coastcross-1 (Cynodon dactylon (L.) Pers) sob diferentes níveis de matéria seca residual. Revista Brasileira de Zootecnia, v.30, n.3, p.627-635, 2001.

BORTOLUSSI, G.; TERNOUTH, J.H.; McMENIMAN, N.P. Dietary nitrogen and phosphorus depletion in cattle and their effects on liveweight gain, blood metabolite concentrations and phosphorus kinetics. Journal of Agricultural Science, v.126, n.4, p.493-501, 1996 .

BROUGHAM, R.W. Intercepton of light by the foliage of pure and mixed stands of pasture plants. Australian Journal of Agriculture Research, v.9, p.39-52, 1957.

BUTTERWORTH, M.H. Phosphorus and their correction. In: BUTTERWORTH, M.H. Beef cattle nutrition and tropical pastures. London: Longman, 1985. p.40-75.

CAMPBELL, A.G. Grazed pastures parameters: I. Pasture dry-matter production and availability in a stocking rate and grazing management experiment with dairy cows. Journal of Agriculture Science, v.67, p.211-216, 1966.

CORSI, M.; MARTHA JR., G.B. Manejo de pastagens para produção de carne e leite. In: SIMPÓSIO SOBRE MANEJO DA PASTAGEM, 15., 1998, Piracicaba. Palestras... Piracicaba: Fundação de Estudos Agrários Luiz de Queiroz, 1998. 296p.

DA SILVA, S.C.; PEDREIRA, C.G.S. Princípios de ecologia aplicados ao manejo de pastagem. In: SIMPÓSIO SOBRE ECOSSISTEMAS DE PASTAGENS, v.3, 1997, Jaboticabal. Anais... Jaboticabal: FUNEP, 1997. p.1-62.

DAYRELL, M.S. Desempenho de bovinos alimentados durante longos períodos com fosfato de Tapira. In: MINI SIMPÓSIO DO COLÉGIO BRASILEIRO DE NUTRIÇÃO ANIMAL, 4., 1991. Campinas. Anais... Campinas: [s.n.], 1991. p.167-176.

DUARTE, H.C.; GRAÇA, D.S.; BORGES, F.M.O.; DI PAULA, O.J. Comparação de métodos in vitro para determinação da biodisponibilidade de fósforo. Arquivo Brasileiro de Medicina Veterinária e Zootecnia, v.55, n.1, p.80-84, 2003.

EUCLIDES, V.P.B., MEDEIROS, S.R. Suplementação animal em pastagens e seu impacto na utilização da pastagem. In: TEORIA E PRÁTICA DA PRODUÇÃO ANIMAL EM PASTAGENS, Anais... Piracicaba: Fundação de Estudos Agrários Luiz de Queiroz, 2005.p.33-70.

FISKE, C.H.; SUBBAROW, Y. The colorimetric determination of phosphorus. Journal of Biological Chemistry, v.66, p.375, 1925 .

GARDNER, A.L. Técnicas de pesquisa em pastagens e aplicabilidade de resultados em sistemas de produção. Brasília: IICA/EMBRAPA-CNPGL, 1986. 197p. (Série publicações miscelâneas, 634).
HODGSON, J. Grazing management: science into practice. Essex: Longman Handbooks in Agriculture, 1990. 203p.

HOLDEN, L.A. Comparation of methods of in vitro dry matter digestibility for ten feeds. Journal Dairy Science, v.82, n.8, p.1791-1794, 1999.

LITTLE, D.A.; ROBINSON, P.J.; PLAYNE, M.J. et al. Factors affecting blood inorganic phosphorus in cattle. Australian Veterinary Journal, v.47, p.153, 1971.

MALAVOlTA, E.; VITTI, G.C.; OLIVEIRA, S.A. Avaliação do estado nutricional das plantas - princípios e aplicações. 2.ed. Piracicaba: POTAFOS, 1997. 319p.

MINSON, D.J. Forage in ruminant nutrition. New York: Academic, 1990. 483p.

MOORE, J.E.; KUNKLE, W.; BROWN, W.F. Forage quality and the need for protein and energy supplements. In: FLORIDA BEEF CATTLE SHORT COURSE, 1991. Gainesville. Proceedings... Gainesville: University of Florida, 1991. p.196.

MOREIRA, F.B.; PRADO, I.N.; CECATO, U. et al. Níveis de suplementação com sal mineral proteinado para novilhos nelore terminados em pastagem no período de baixa produção forrageira. Revista Brasileira de Zootecnia, v.33, n.6, p.1814-1821, 2004.

MOTT, G.O.; LUCAS, H.L. The design, conduct and interpretation of grazing trials on cultivated and improved pastures. In: INTERNATIONAL GRASSLAND CONGRESS, 1952, Pensylvania. Proceedings... Pensylvania: State College Press, 1952. p.1385.

NAITO, Y.; SAT, R.; MURAKAMI, D. Plasma osteocalcin in preparturient and postparturient cows: correlation with plasma 1,25-dihydroxyvitamin D, calcium and inorganic phosphorus. Journal Dairy Science, v.73, p.3481-3484, 1990.

NATIONAL RESEARCH COUNCIL - NRC. Feed phosphorus shortage: level and sources of phosphorus recommended for livestock and poultry. Washington, D.C.: National Academy of Science, 1974. 38p.

NATIONAL RESEARCH COUNCIL - NRC. Nutrient requeriments of beef cattle. 7.ed. Washington, D.C.: National Academy Press, 1996. 242p

NICODEMO, M.L.F.; MORAES, S.S. Esclarecimentos sobre o uso de fontes alternativas de fósforo para bovinos. Campo Grande: EMBRAPA-CNPGC, 2000. 4p. (Boletim Técnico, 37).

NICODEMO, M.L.F.; MORAES, S.S.; THIAGO, L.R.L. et al. Metabolismo ósseo de vacas jovens nelore em pastos de Brachiaria brizantha suplementados ou não durante a seca com fósforo/cálcio e concentrado. Revista Brasileira de Zootecnia, v.34, n.1, p.316-326, 2005 .

NIELSEN, H.K. Circadian and circatrigintan changes in osteoblastic activity assessed by serum osteocalcin. Danish Medical Bulletin, n.41, p.216-227, 1994.

NUSSIO, L.G.; MANZANO, R.P.; PEDREIRA, C.G.S. Valor alimentício em plantas do gênero Cynodon. In: SIMPÓSIO SOBRE MANEJO DA PASTAGEM, 15., 1998, Piracicaba. Palestras... Piracicaba: Fundação de Estudos Agrários Luiz de Queiroz, 1998. p.296.

OLIVEIRA, M.A.; PEREIRA, O.G.; GARCIA, R. et al. Rendimento e valor nutritivo do capim-tifton 85 (Cynodon spp.) em diferentes idades de rebrota. Revista Brasileira de Zootecnia, v.29, n.6, p.1949-1960, 2000.

PEDREIRA, J.V.S.; MATTOS, H.B. Crescimento estacional de vinte e cinco espécies ou variedades de capins. Boletim de Indústria Animal, v.38, n.2, p.117-143, 1981.

PEDREIRA, M.S.; BERCHIELLI, T.T. Minerais. In: BERCHIELLI, T.T.; PIRES, A.V.; OLIVEIRA, S.G. Nutrição de ruminantes. Jaboticabal: FUNEP, 2006. p.333-353.

PRADO, H. Solos do Brasil - Gênese, morfologia, classificação, levantamento e manejo. 3.ed. Piracicaba, 2003. 275p.

PROHMANN, P.E.F.; BRANCO, A.F.; JOBIM, C.C. et al. Suplementação de bovinos em pastagem de Coastcross (Cynodon dactylon (L.) Pers) no verão. Revista Brasileira de Zootecnia, v.33, n.3, p.792-800, 2004. 
SILVA FILHO, J.C.; LOPES, H.O.S.; PEREIRA, E.A. et al. Absorção real do fósforo do fosfato bicálcico, fosfato de monoamônio, superfosfato triplo e do fosfato de uréia em bovinos. Pesquisa Agropecuária Brasileira, v.21, n.1, p.1-6, 1992.

SINGER, L.; ARMSTROG, W.D. Determination of fluoride in bone with the fluoride eletrode. Analytical Chemistry, v.40, p.613, 1968 .

SNIFFEN, C.J.; O'CONNOR, J.D.; VAN SOEST, P.J. et al. A net carbohydrate and protein system for evaluation cttle diets: II. Carbohydrates and protein avaliability. Journal of Animal Science, v.70, n.11, p.3562-3577, 1992.

STATISTICAL ANALYSIS SYSTEM - SAS. SAS/STAT. User's guide, version 8.2 (Compact Disc). Cary, 2001.

THOMPSON JUNIOR, W.R. Phosphorus in animal nutrition. In: POTASH AND PHOSPHATE INSTITUTE. Phosphorus for agriculture a situation analysis. Atlanta, p.126-158, 1978.

TILLEY, J.M.A.; TERRY, R.A. A two stage technique for the "in vitro" digestion of forage crop. Journal of Britain Grassland Society, v.18, p.104, 1963.
UNDERWOOD, B.J. The mineral nutrition of livestock Farnham Royal: CAB, 3.ed. 1981. 180p.

VAN SOEST, P.J. Minerals. In: ___ Nutritional ecology of the ruminant. 2.ed. Nova York: Cornel University Press, 1994. p. $122-139$.

VAN SOEST, P.J.; ROBERTSON, J.B.; LEWIS, B.A. Symposium: Methods for dietary fiber, neutral detergent fiber, and nonstarch polysaccharides in relation to animal nutrition. Journal of Dairy Science, v.74, p.3583, 1991.

VITTI, D.M.S.S.; ABDALLA, A.L.; MEIRELLES, C.F. Absorção real do fósforo de diferentes fontes para ovinos através do uso de radiofósforo (P-32). Pesquisa Agropecuária Brasileira v.27, n.10, p.1405-1408, 1992.

WEISS, W.P. Energy prediction equations for ruminant feeds. In: CORNELL NUTRITION CONFERENCE FOR FEED MANUfACTURERS, Rochester, 1999. Proceedings... Rochester: New York State College of Agriculture \& Life Sciences, Cornell University, p.176-185, 1999.

WILM, H.G.; COSTELO, O.F.; KLIPPLE, G.E. Estimating forage yield by the double sampling method. Journal of American Society of Agronomy, v.36, p.194-203, 1944. 